\title{
TECHNOLOGICAL CAPABILITIES OF VIBRATION TREATMENT OF WELDED STRUCTURES (REVIEW)
}

\author{
G.I. LASHCHENKO \\ E.O. Paton Electric Welding Institute, NASU \\ 11 Kazimir Malevich Str., 03680, Kiev, Ukraine. E-mail: office@paton.kiev.ua
}

\begin{abstract}
Analysis of technological capabilities of postweld vibration treatment and vibration treatment during welding was performed on the basis of available publications. It is shown that the technology of postweld vibration treatment is an effective means of lowering residual stresses and increasing dimensional stability of beam, frame and casing structures (machine-tool construction, mechanical engineering, shipbuilding, etc.) made of steel, titanium and aluminium alloys. Compared to high tempering, power consumption is reduced tens of times and productivity is increased. Vibration treatment during welding and surfacing is an effective means of lowering residual stresses, increasing mechanical properties and performance of structures, and improving weldability of a number of steel grades. However, experience of industrial application of this technology is so far insufficient for formulating clear recommendations on specific fields of its application. 41 Ref., 3 Figures.
\end{abstract}

Keywords : welded structures, residual stresses, vibration treatment, dimensional instability, increased fatigue resistance, weldability

Residual welding stresses are an undesirable concomitant factor in welded joint formation. They, as a rule, have a negative influence on accuracy, corrosion resistance, endurance at dynamic loads and operational reliability of welded structures [1]. It is not always possible to sufficiently minimize their negative influence on the welded structure using pre-welding measures, as well as those performed during welding. Therefore, postweld heat treatment is used in a number of cases, which usually consists in thermal tempering of welded structures.

At the same time, known are a number of technologies, which allow reducing power consumption for postweld treatment of welded structures due to application of peening, ultrasonic impact treatment (high-frequency mechanical peening), shot peening, explosion treatment, static loading, vibration treatment, etc. [2]. All of them have their advantages, disadvantages and rational fields of application.

The objective of this work is analysis of technological capabilities of vibration treatment and substantiation of possible fields of its industrial application.

Postweld vibration treatment. Postweld vibration treatment is performed by excitation of low-frequency mechanical oscillations in the welded structure. Alternating stresses develop here, which are summed up with residual welding stresses. Microplastic and, under certain conditions, also macroplastic deformations proceed, which promote redistribution and lowering of residual stresses.

(c) G.I. LASHCHENKO, 2016
Vibration treatment is performed in the mode of non-resonant and resonant loading. Treatment at non-resonant frequencies has limited application, and is usually suitable for low rigidity structures.

In the case of resonant vibration loading, development of high amplitudes of dynamic stresses is ensured in the metal structure, that has a significant influence on redistribution of stresses in the entire volume of the material.

Starting from 1960 up to 1990, investigations of the process of vibration treatment and its industrial application have been intensively pursued in the USSR, USA, Great Britain, Poland, China and other countries. The main results of the performed work are summarized in a number of publications [3-10]. In 2000, the interest to postweld vibration treatment also remained quite noticeable [11-22].

Known are various technological schemes of postweld vibration treatment of metal structures $[8,10]$.

The most common scheme of vibration treatment envisages mounting the welded structure on anti-vibration supports and fastening a vibration exciter with adjustable frequency to it. Resonant frequencies of welded structure-fixture-exciter system are registered by a smooth variation of vibration frequency from minimal to maximal values. Then vibration treatment is performed on selected resonant frequencies.

Control of the mode of vibration treatment by this and similar schemes with unbalance exciter is performed by energy (by the value of energy, transmitted to the structure), amplitude (by resonance peak shift) 
and phase (by the change of phase shift between the driving force and forced vibrations) methods.

Composition of a modern technological complex for vibration treatment includes vibration exciter with AC motor accelerometer, measuring amplifier, rectifier, inverter, indicators of motor current frequency and amplitude of item vibrations, recorder or PC $[10,12,16]$.

Development of vibration treatment technology necessitates preliminary determination of natural frequency of structure vibrations.

For simple beam-type structures with constant longitudinal rigidity, natural frequency of vibrations $\omega$ can be determined with sufficient accuracy from the following formula [16]:

$$
\omega=\frac{\pi^{2} n^{2}}{l^{2}} \sqrt{\frac{E I_{x}}{m_{0}}},
$$

where $n$ is the number of natural vibration form; $l$ is the spacing of anti-vibration supports; $E I_{x}$ is the bending stiffness of the beam in the longitudinal direction; $m_{0}$ is the mass per a unit length of the beam.

It is known that the number of natural vibration form determines the number of half-waves of beam elastic axis at its vibrations.

At transition to a higher resonant frequency, the number of half-waves along beam length becomes greater, and sections developing maximum normal stresses, caused by vibration loading, are located closer to each other.

Simple analytical dependencies cannot be used at determination of resonant frequencies and natural vibration forms for complex structures of variable rigidity. It is recommended to perform such calculations by numerical methods, in particular, by finite element method. So, in [16], ANSYS software package was used for these purposes. It allows determination of natural frequencies of the model and studying its behaviour under the impact of harmonically alternating loads.

Magnetically anisotropic scanner-flaw detector «Kompleks-2» was used, when optimizing the technology of monitoring the change of residual stresses after vibration treatment. The instrument generates maps of the difference of principal mechanical stresses, concentrators of local mechanical stresses, as well as the coefficient of stress distribution non-uniformity [16].

So-called structural vibration is also used for stabilization of geometrical parameters of metal-cutting equipment. In this case, vibration loading of base parts of machine tools is performed through technological modes of plank cutting. In [22], a procedure was proposed for determination of dynamic load for vibration treatment of bed plates by this method.

To eliminate residual deformations of welded structures, it is proposed to apply a combined loading in the form of static tension or bending in combination with vibration treatment $[5,10]$. These technologies did not become extensively applied in industry. Many years of practical experience showed that postweld vibration treatment is an effective means of improving the dimensional stability of welded structures [3-12]. In practice, dimensional instability of items, in particular welded structures, is the result of relaxation processes and creep, running in the material and the welded joint under the impact of applied structural (operational) and residual inner stresses [6]. Relaxation processes develop particularly intensively in alloys with metastable phase and structural state (in steels this is transformation of residual austenite into martensite and tempering of quenching martensite).

Dimensional instability of welded structures is affected by a number of design-technological factors: base material, structural rigidity of the joint, thermodeformational cycle, applied welding consumables.

In production, instability of structural dimensions of welded structures can be manifested at the stage of machining, during maturing, at the change of temperature conditions, as well as in operation under the impact of service load. Therefore, stabilizing vibration treatment is usually performed prior to machining, or 2 times - before rough and before finish machining.

Vibration treatment of steel metal structures from carbon and low-alloyed steels allows reducing stresses of the first kind to $50-60 \%$ and those of the second kind - to $45 \%$.

In the case of treatment of structures from titanium alloys, stresses of the first kind decrease to $60-65 \%$, and in aluminium ones - to $70-75 \%[4,10,11]$.

Stabilizing vibration treatment is extensively used in machine-tool construction in production of welded and cast base parts (bases, bed frames, traverses, etc.), in shipbuilding (submarine hulls from titanium alloys. hull steel and aluminium parts of ships, etc.), in power, transportation and others engineering sectors, including manufacture of defense equipment [8-12].

Power consumption at postweld treatment of metal structures of up to $10 \mathrm{t}$ weight and more is approximately 50 times lower than that at general tempering, while productivity is 15-20 times higher [10].

As regards application of postweld vibration treatment to increase corrosion resistance of welded joints, we can refer to information given in [13, 14]. It is evidently insufficient for determination of rational fields of application of postweld treatment for these purposes. Additional research is required.

Speaking about applicability of vibration treatment to improve welded joint fatigue resistance, some studies have suggested that even a lowering of cyclic fatigue life can be anticipated as a result of accumu- 


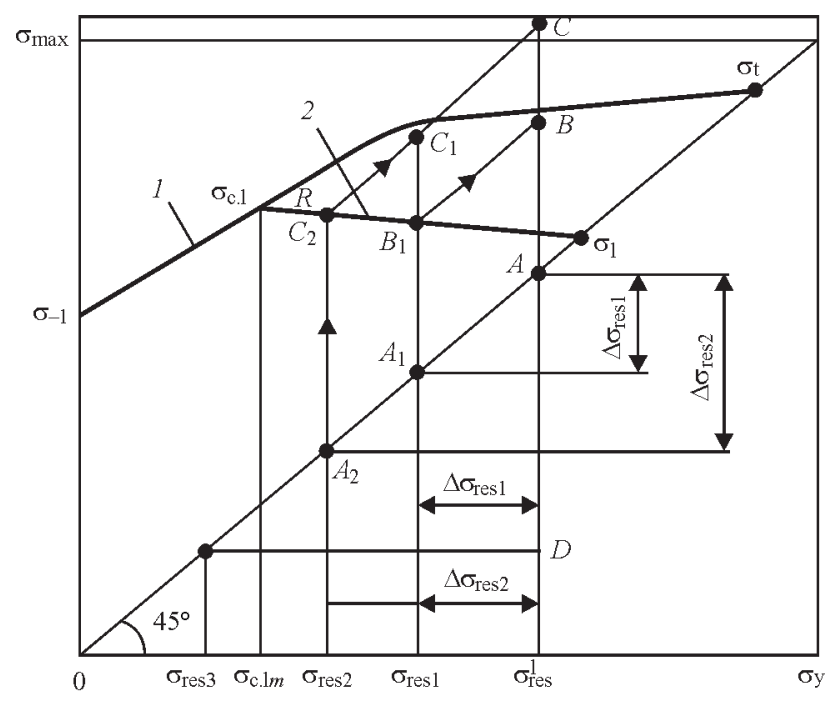

Figure 1. Assigning non-damaging modes of vibration treatment of metal structures to lower residual tensile stresses in them by a value not lower than the specified one [15] (for designations see the text)

lation of fatigue damage during treatment $[1,7]$. Obtained result largely depends on overloading stresses and treatment duration. Therefore, to avoid possible initiation of fatigue cracks at the technological stage, a procedure was developed for determination of non-damaging modes of vibration treatment of welded joints, providing lowering of residual stresses by the specified value [15].

This procedure is based on application of a complex program of limit cycle stresses, plotted in the coordinates of maximum stress $\sigma_{\max }$-mean stresses $\sigma_{y}$ (Figure 1). Line 1 corresponds to endurance limit $\sigma_{R}$ of welded joint (structure) and is limited by endurance limit at symmetrical loading $\sigma_{-1}$ and ultimate strength $\sigma_{t}$, and line 2 - by the cyclic creep limit of structure material $\sigma_{\text {c.c. } .}$. The latter is limited by creep limit under static loading $\sigma_{c}$ (yield limit $\sigma_{\mathrm{y}}$ is allowed), and endurance limit, called minimum cyclic creep limit $\sigma_{c c}$, at which the specified value of plastic deformation $\varepsilon_{\mathrm{pl}}$ is achieved. In development of vibration treatment technology the curve of residual stresses (RS) in a certain zone of welded structure is first determined experimentally, and maximum value of tensile RS $\sigma_{\text {res }}^{l}$ is plotted in the diagram (p·A). Value of stress $\sigma_{\text {res } 1}^{\text {res }}(\mathrm{p} \cdot \mathrm{A})$, to which $\sigma_{\text {res }}^{1}$ should be reduced, is assigned. For correct selection of the load, which would allow reducing RS by a value not less that $\Delta \sigma_{\text {resi }}$, it is necessary for line 2 to correspond to plastic deformation $\varepsilon_{\mathrm{pl}}$, determined from condition $\Delta \sigma_{\text {res } 1}=E \varepsilon_{\mathrm{pl}}$. Stress from external load $\sigma_{\text {ex.l. }}$, which should be applied to the structure, is determined from the following condition:

$$
\sigma_{\text {c.lR }}<\sigma_{\text {ex.l }}+\sigma_{\text {res }}^{1}<\sigma_{R},
$$

where $\sigma_{R}, \sigma_{c . l R}$ are the stresses, corresponding to the points of intersection of cyclic stress impact with lim- it stress lines 1 and 2, respectively. Thus, condition $\sigma_{\text {ex.l }}+\sigma_{\text {res }}^{1}<\sigma_{R}$ ensures absence of fatigue damage after vibration treatment, and $\sigma_{\text {c.lR }}<\sigma_{\text {ex.l }}+\sigma_{\text {res }}^{1}-$ an effective lowering of RS.

The diagram allows analyzing multistep application of vibration load to lower residual stresses by value $\Delta \sigma_{\text {res1 } 1}, \Delta \sigma_{\text {res2 } 2}, \Delta \sigma_{\text {res3 }}$ and the thus achieved lowering of residual stresses $\sigma_{\text {res1 } 1}, \sigma_{\text {res2 }}$ or $\sigma_{\text {res3 } 3}$. In the latter case, it is recommended to apply asymmetrical load: $\sigma_{m}=A D, \sigma_{\mathrm{a}}=A B$, for lowering initial residual stresses $\sigma_{\text {res3 }}$, which are lower than the mean stress of minimum cyclic creep limit $\sigma_{\text {c.lm }}$. If the condition of RS lowering by a value not smaller than the assigned one is not specified, loading modes can be selected arbitrarily, while following condition (2).

Proceeding from application of the above procedure in [15], we came to the conclusion that vibration treatment can be applied to extend the fatigue life of only non-critical structures.

Vibration loading during welding. Technologies using vibration loading during welding have attracted greater attention over the recent years [23-30]. Positive influence of low-frequency mechanical vibration of the item being welded on lowering of residual stresses and strains, increase of weld resistance to formation of solidification cracks and pores, improvement of mechanical properties is noted in a number of studies conducted already in 1980s [31]. Vibration treatment was regarded as one of the methods, designed to influence the processes running in the welding arc, in liquid and solidifying metal of the weld pool, and adjacent base metal region, with the purpose of integrated improvement of welded joint properties. In this period, respective practical results were obtained, which have found partial application in industry.

In recently published work [23], the influence of vibration during welding on cold resistance of welded joints $10 \mathrm{~mm}$ thick from low-alloyed steel 09G2S was studied. Two-sided submerged-arc welding was performed, and vibration loading was applied by a schematic, given in Figure 2, at the frequency of 50, 100, 150 and $200 \mathrm{~Hz}$ with 0.8-1.0 mm amplitude.

Excitation of low-frequency vibrations in molten metal of weld pool and in adjacent zones, leads to reduction of mean area of grains in different sections of welded joints. Here, maximum reduction of mean area of grains of HAZ and weld metal is achieved by concomitant vibration impact of $150 \mathrm{~Hz}$ and is equal to $32 \%$ for HAZ metal and $25 \%$ for welds, compared to untreated samples. Surface stresses were also decreased to a maximum at the same vibration frequency, which were determined by X-ray structural analysis (Figure 3). 
It is noted that with increase of frequency of concomitant vibration impact an increase of impact toughness $K C V$ of welded joint metal takes place. Here, maximum increase, compared to untreated samples, was achieved at the frequency of $150 \mathrm{~Hz}$ and was equal to $24 \%$ for samples, tested at $20{ }^{\circ} \mathrm{C}$, and $50 \%$ for samples tested at $-40{ }^{\circ} \mathrm{C}$.

The authors believe that the considered welding technology can be used in fabrication of metal structures with extended welds, operating under the conditions of considerable gradient of ambient temperatures.

Work [24] is a study of applicability of vibration treatment instead of preheating in welding of petroleum processing equipment parts from $12 \mathrm{MKh}$ steel. Samples were welded by manual arc welding with TsU-2MKh electrodes. It is found that in welding with vibration loading (50, 100 and $150 \mathrm{~Hz}$ frequency, 0.8 mm amplitude) weld metal structure has higher dispersion and uniformity. A bainitic structure forms in the HAZ metal. Level of residual welding stresses decreases by $16-19 \%$, compared to preheating. Mechanical properties of weld metal and near-weld zone are improved. For welding critical structures from $12 \mathrm{MKh}$ steel, it is recommended to use two vibration devices, operating in anti-phase [20, 21]. A process was patented of lowering RS in welded joints, according to which application of vibrations is performed during welding in the transverse direction in the vertical plane, normal to weld axis, from two exciters operating in anti-phase at frequencies from 50 up to $300 \mathrm{~Hz}$ with up to $0.8-1.0 \mathrm{~mm}$ amplitude and located symmetrically relative to weld axis on each of the edges being welded (see Figure 3) [26].

Another patent [27] describes the process of reducing RS in welded joints of pipelines, according to which application of low-frequency vibrations by vibration devices is performed during welding. Vibration frequency is equal to that of natural vibrations of pipeline section with welded joint between rigid fastening points.

Investigations were conducted to establish the impact of vibrations on the weld pool and the adjacent zone during welding cycle, in order to study their influence on strength properties of weld metal and susceptibility to intercrystalline corrosion (ICC) of joints from 12Kh18N10T steel [28]. Vibration loading was performed at the frequency of 50 and $100 \mathrm{~Hz}$ with 0.6-0.8 mm amplitude.

Test results showed that samples welded without vibration treatment turned out to be susceptible to ICC. Samples produced with application of vibration treatment, demonstrated resistance to ICC without cracking in bending. The authors attribute it to re-

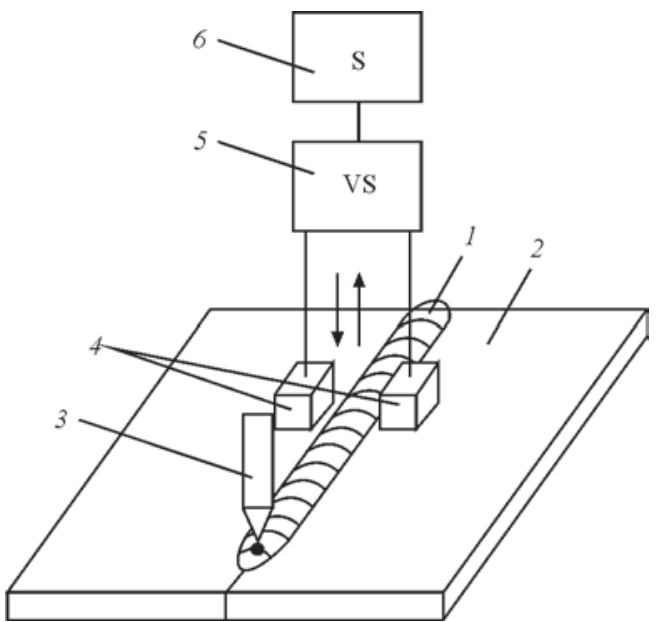

Figure 2. Schematic of vibration application during welding: 1 - weld; 2 - item being welded; 3 - electrode; 4 - vibration device; 5 - vibration synchronizer; 6 - vibration energy source [23]

finement of weld metal dendritic structure, leading to extension of grain boundaries that results in loading of continuous carbide network and reduction of the amount of carbides per a unit of grain boundary length.

Vibration treatment at $50 \mathrm{~Hz}$ frequency increases the value of weld metal impact toughness by $21 \%$, and treatment at $100 \mathrm{~Hz}$ - by $25 \%$.

Lowering of RS at vibration loading during welding (50 and $100 \mathrm{~Hz}$ ) results in increase of fatigue fracture resistance of welded joints from 12Kh18N10T steel by $18-22 \%$.

Results similar to those given above were derived by the authors in welding two-layer steel 09G2S + 12Kh18N10T with application of low-frequency vibration treatment [30].

Vibration has a positive influence on formation of structure and properties of castings metal [32]. Under the impact of vibration, the melt is intensively mixed, and growing crystals break off, new solidification centers are created in liquid metal volume, temperature gradient across the section decreases and bulk solidification is ensured. A more uniform crystalline structure of the ingots, which forms under the impact

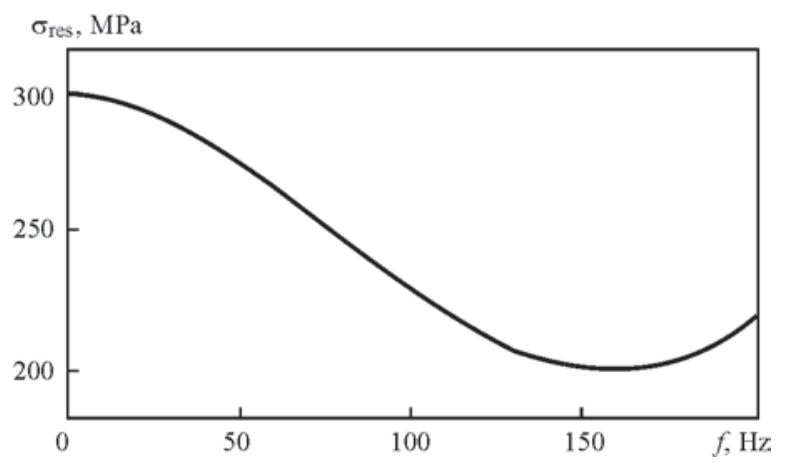

Figure 3. Residual stresses of the $3^{\text {rd }}$ kind versus frequency of concomitant vibration impact [23] 
of vibration, provides lower anisotropy of properties of structural components (individual crystals) and, consequently, smaller RS.

Conducted studies on determination by the method of laser interferometry - electron speckle-interferometry of RS in ingots of Kh18N9T steel showed that residual stresses decrease by $20-29 \%$ under the impact of vibration loading ( $0.5 \mathrm{~mm}$ amplitude, 60 $80 \mathrm{~Hz}$ frequency) [30]. In the same work the authors give experimental data on lowering of RS by up to 2.5 times under the impact of vibration in welding of samples from St.3 steel. It is emphasized that low-frequency vibration (up to $200 \mathrm{~Hz}$ frequency, up to $1 \mathrm{~mm}$ amplitude) leads to refinement of weld metal structure and to considerable reduction of the quantity of pores. More over, vibration has a positive influence on dispersion of nonmetallic inclusions, their quantity and nature of distribution in the weld.

The possibility of refining the structure and improving the deposited metal properties in induction surfacing is reported in several publications [33-36]. In this case the part is subjected to vertical or horizontal vibration at the moment, when powder-like charge is in the molten state. Direction of vibrations application, as well as their frequency and amplitude, are essential.

Experiments on induction surfacing with powders from high-carbon alloy PG-S (grade 1) with vibration amplitude of $0.2 \mathrm{~mm}$ and $50 \mathrm{~Hz}$ frequency showed that horizontal vibration leads to a noticeable refinement of the carbide component [33]. Carbides, having the form of a hexagon with average long side of 10-12 $\mu \mathrm{m}$ (in the case of surfacing without vibration), are refined to $7-10 \mu \mathrm{m}$ at vertical and to $3.5-7.0 \mu \mathrm{m}$ at horizontal vibration. Here, the highest hardness and wear resistance were demonstrated by samples, surfaced with horizontal vibration. The authors attribute it to favourable structure of deposited metal and formation of a greater quantity of carbides $(\mathrm{Fe}, \mathrm{Cr})_{7} \mathrm{C}_{3}$ that is confirmed by the results of microprobe analysis.

Works [37-39] report an improvement of weldability of 20KhGSFL, 15Kh5M and 12Kh17 steels under the impact of vibrations during arc welding. This is also confirmed by the data given in [31].

It is known that in welding steels with a high carbon equivalent, particularly high-strength steels, there arises the risk of cold cracking [40]. These cracks most often initiate in hear-weld zone. A mandatory condition for cold crack initiation and propagation is presence of quenching structures, a certain quantity of diffusible hydrogen and tensile stresses.

According to the above data of [23-25, 31, 37-39] vibration treatment in welding promotes a refinement of weld and HAZ metal structure, while tensile stresses decrease markedly. Moreover, intensive mixing of the weld pool should promote hydrogen desorption. This leads to a suggestion of the rationality of application of concomitant vibration treatment in high-strength steel welding. However, many points require verification. It is known that the thermodeformational cycle of welding leads to a significant inhomogeneity of hydrogen field concentration [41]. In case of concomitant vibration treatment, deformational component of the cycle changes noticeably, that certainly influences redistribution of dislocations and their interaction with hydrogen. Here, dislocations have the role of hydrogen traps and under certain conditions they can both increase and lower the risk of cold cracking.

\section{Conclusions}

Experience of industrial application of postweld vibration treatment gained over the last decades is indicative of this technology being an effective tool for improvement of dimensional stability of steel welded base parts of metal-working equipment (bed plates, pillar bases, etc.), frame and casing parts for power engineering, various parts for shipbuilding and defense engineering, including also those from titanium and aluminium alloys. Here, the extent of lowering of residual stresses of the first kind can reach 50-60\%, while power consumption will decrease by up to 50 times, compared to overall tempering.

Postweld vibration treatment in a specific mode range promotes certain increase of fatigue resistance, and can be used to increase fatigue life of non-critical welded structures. By this parameter it is inferior to other technologies, in particular, to peening.

Numerous publications are indicative of the fact that vibration treatment during welding and surfacing is an effective tool for lowering residual stresses, increasing mechanical and service properties, and improvement of weldability of a number of steel grades. However, experience of industrial application of vibration treatment during welding is so far insufficient to formulate clear recommendations on specific fields of its application.

1. (1993) Welded building structures. Vol. 1: Principles of structure design. Ed. by L.M. Lobanov. Kiev: Naukova Dumka.

2. Lashchenko, G.I., Demchenko, Yu.V. (2008) Energy-saving technologies of postweld treatment of metal structures. Kiev: Ekotekhnologiya.

3. Pisarenko, V.S., Verzhbinskaya, N.I. (1972) Decrease of residual stresses by vibration treatment (Review). Moscow: NII Informtyazhmash.

4. Gruzd, A.A. (1973) Examination of welded structure deformations in time and searching for methods for their accounting and stabilizing. Kiev: PWI.

5. Sagalevich, V.M. (1974) Methods of elimination of welding strains and stresses. Moscow: Mashinostroenie. 
6. Sagalevich, V.M., Saveliev, V.F. (1986) Stability of welded joints and structures. Moscow: Mashinostroenie.

7. Dawson, R., Moffat, D.G. (1980) Vibration stress relief. In: Proc. of ASM on Theor. Principles of Eng. Calculations, 2, $1-9$.

8. Ragulskis, K.M., Stupilnas, B.B., Tolutas, K.B. (1987) Vibration ageing. Leningrad: Mashinostroenie.

9. Sedek, P. (1990) Stabilisacja wibracyjna konstrukcji spawanych. Przeglad Spawalnictwa, 7, 16-18.

10. Lashchenko, G.I. (2001) Vibration treatment of welded structures. Kiev: Ekotekhnologiya.

11. Gorbach, V.D., Sokolov, O.G., Mikhajlov, V.S. (2003) Problems of welding and fatigue life of welded structures in shipbuilding. The Paton Welding J., 10/11, 158-163.

12. Dryga, A.I. (2004) Vibrostabilizing treatment of welded and cast parts in machine-building (theory, studies, technology). Kramatorsk: DGMA.

13. Xhou Wei, Chen Hui (2012) Study of possibility for decrease of stresses in joints from steel SWA490BW resistant to atmosphere corrosion using vibration treatment. Dian Hanji-Elec. Welding Mach., 9, 62-65.

14. Babichev, A.P., Butenko, V.I., Chukarin, A.N. et al. (2014) Improvement of resistance of welded joints. Uprochn. Tekhnologii i Pokrytiya, 6, 3-6.

15. Degtyaryov, V.A. (2013) Effect of strengthening treatment of welded joints on increase of their fatigue resistance. Problemy Prochnosti, 5, 85-103.

16. Grigoriants, A.G., Shiganov, I.N., Misyurov, A.I. et al. (2014) Technologies of low-frequency vibrotreatment of welded joints in machine-building. Svarochn. Proizvodstvo, 6, 19-23.

17. Rao, D., Wang, D., Chen, L. et al. (2007) The effectiveness evaluation of 314L stainless steel vibratory stress relief by dynamic stress. Int. J. Fatigue, 29.

18. Zhao, X.C., Zhang, Y.D., Zhang, H.W. et al. (2008) Simulation of vibration stress relief after welding based on FEM. Acta Metall. Sin., 21(21).

19. Sedek, P., Welzel, M., Kwiecinski, K. (2016) Stabilizazja wibrayjna - staly rozwoj dla praktyki przemyslowej. Biul. Inst. Spawalnictwa, 1, 29-35.

20. Yang, Y.P., Jung, C., Yancey, R. (2005) Finite element modeling of vibration stress relief after welding. In: Proc. of 7th Conf. on Trends in Welding Research (USA, May 16-20, 2005).

21. Klauba, B.B., Adams, C.M., Berry, J.T. (2005) Vibratory stress relief: Methods used to monitor and document effective treatment. A survey of users and directions for further research. Ibid.

22. Filippov, Yu.A., Amelchenko, N.A., Ruchkin, L.V. et al. (2002) Theoretical aspects of ageing vibrotechnologies of non-standard equipment welded bodies. Tekhnologiya Mashinostroeniya, 4, 33-35.

23. Karetnikov, V.D., Rizvanov, R.G., Fajrushin, A.I. et al. (2014) Increase in reliability of gas-oil equipment operating under conditions of abrupt thermal gradient. Ibid., 4, 33-37.

24. Abdullin, T.Z., Ibragimov, I.G., Fajrushin, A.M. (2013) Study of vibration treatment effect during welding on mechanical properties of welded joints. Svarka i Diagnostika, 1, 36-38.

25. Abdullin, T.Z. (2013) Improvement of technology for production of welding equipment from heat-resistant steel
12MKh: Syn. of Thesis for Cand. of Techn. Sci. Degree. Ufa: UfaGNTU.

26. Fajrushin, A.M., Karetnikov, D.V., Zaritov, M.Z. et al. Method of residual stress relaxation in welded joints of metals. Pat. 2424885 Russia. Publ. 27.07.2011.

27. Bolotov, V.I., Khafizov, O.F., Fajrushin, A.M. et al. Method of residual stress relaxation in welded joints of pipelines. Pat. 2492037 Russia. Publ. 10.09.2013.

28. Akhtyamov, R.M., Ibragimov, I.G., Zaripov, M.Z. et al. (2013) Increase in strength of $12 \mathrm{Kh} 18 \mathrm{~N} 10 \mathrm{~T}$ steel welded joints using low-frequency vibration treatment during welding. Uprochn. Tekhnologii i Pokrytiya, 1, 38-41.

29. Akhtyamov, R.M., Zaripov, M.Z., Fajrushin, A.M. (2012) Increase in strength of welded joints of two-layer 09G2S+12Kh18N10T steel using low-frequency vibration treatment during welding. In: Proc. of 5th Sci.-Pract. Conf. on Engineering and Tekhnology. New Prospects of Development (Moscow, 18 Apr. 2012), 8.

30. Nuradinov, A.S., Efimov, V.A., Taranov, E.D. et al. (2004) Effect of vibration on formation of macro- and microstructure of solidified steel ingots. Materialovedenie, 5, 24-26.

31. Lashchenko, G.I. (2006) Methods of consumable electrode arc welding. Kiev: Ekotekhnologiya.

32. Nuradinov, A.S., Eldarkhanov, A.S., Taranov, E.D. (2012) Effect of vibration on residual stresses in ingots and welds. Stal, 4, 19-20.

33. Pulka, Ch.V., Shably, O.N., Senchishin, V.S. et al. (2012) Influence of vibration of parts on structure and properties of metal in surfacing. The Paton Welding J., 1, 23-25.

34. Shably, O.N., Pulka, Ch.V., Senchishin, V.S. Method of surfacing of thin flat steel parts. Pat. on ut. mod. UA 54204. Int. Cl. B23K 13/00. Publ. 25.10.2010.

35. Pulka, Ch.V., Senchishin, V.S. Device for surfacing of thin shaped discs. Pat. on ut. mod. UA 59994. Int. Cl. B23K 13/00. Publ. 10.06.2011.

36. Pulka, Ch.V., Senchishin, V.S. Method of surfacing of parts. Pat. on ut. mod. UA 64371. Int. Cl. B23K 13/00. Publ. 10.11.2011.

37. Fajzulin, A.V., Madretdinov, A.I., Karetnikov, V.D. (2012) Repair welding of pump body made from medium-alloy steel 20KhGSFL. In: Proc. of 13th Int. Severgeoeko Junior Sci. Conf. (Ukhta, 21-23 March 2012), Pt 6, 70-72.

38. Rizvanov, R.G., Fajrushin, A.M., Karetnikov, D.V. (2013) Study of influence of vibration treatment on mechanical properties and crack resistance of pipe welded joints from heat-resistant steel 15Kh5M. Neftegaz. Delo, 1, 369-382.

39. Khalimov, D.N., Samigushin, V.V., Fajrushin, A.M. (2013) Study of influence of vibration treatment in welding on mechanical properties of steel $12 \mathrm{Kh} 17$ welded joint. In: Proc. of 64th Sci.-Techn. Conf. of Students, Post-Graduates, Young Scientists of UfaGNTU (Ufa, Russia, 2013), Book 1, 234.

40. Lobanov, L.M., Poznyakov, V.D., Makhnenko, O.V. (2013) Formation of cold cracks in welded joints from high-strength steels with 350-850 MPa yield strength. The Paton Welding J., 7, 7-12.

41. Pokhodnya, I.K., Ignatenko, A.V., Paltsevich, A.P. et al. (2013) Hydrogen-induced cold cracks in welded joints of high-strength low-alloyed steels (Review). Ibid., 5, 2-13. 